\title{
ANALISIS NILAI TOTAL ELECTRON CONTENT (TEC) NEAR REAL TIME MENGGUNAKAN DATA GPS DUA FREKUENSI (STUDI KASUS: SURABAYA)
}

\author{
Mokhamad Nur Cahyadi ${ }^{1}$, Almas Nandityo Rahadyan ${ }^{2}$, Buldan Muslim ${ }^{3}$ \\ 1,2Departemen Teknik Geomatika FTSLK-ITS, Kampus ITS Sukolilo, Surabaya, 60111 \\ ${ }^{3}$ Lembaga Penerbangan dan Antariksa Nasional, Jl. Dr. Junjunan 133, Bandung, 4017 \\ e-mail : cahyadi_geod@yahoo.com ${ }^{1}$, almas.nandityo@gmail.com², mbuldan@gmail.com³
}

\begin{abstract}
Abstrak
Ionosfer adalah bagian dari lapisan atmosfer yang terletak antara 50 sampai $1000 \mathrm{~km}$ diatas permukaan bumi yang terdiri dari elektron-elektron yang dapat mempengaruhi propagasi gelombang elektromagnetik berupa tambahan waktu tempuh dalam penjalaran sinyal, hal ini bergantung pada Total Electron Content (TEC) di ionosfer dan frekuensi sinyal GPS. Dalam penentuan posisi presisi tinggi dengan GPS, pengaruh ionosfer harus diestimasi sehingga koreksi ionosfer dapat ditentukan untuk mengeliminasi pengaruh ionosfer pada pengamatan GPS. Penentuan koreksi ionosfer maka dapat dilakukan dengan perhitungan nilai TEC menggunakan data GPS dual frekuensi dari stasiun referensi atau model. Dalam pembuatan model TEC secara spasial digunakan fungsi polinomial untuk jam tertentu. Hasil pengolahan menunjukkan nilai TEC maksimum terjadi pada siang hari jam 14.00 WIB untuk tanggal 13 Februari 2018 dengan nilai 35,510 TECU dan nilai TEC minimum terjadi pada pagi hari jam 05.00 WIB untuk tanggal 7 Februari 2018 dengan nilai 2,138 TECU. Model TEC secara spasial menunjukkan warna merah pada daerah Surabaya dan sekitarnya untuk nilai TEC tertinggi pada saat siang hari berkisar jam 13.00 WIB hingga 16.00 WIB.
\end{abstract}

Kata Kunci: Ionosfer, TEC, TEC Model

\begin{abstract}
The ionosphere is part of the atmospheric layer located between 50 and $1000 \mathrm{~km}$ above the earth's surface consisting of electrons that can affect the propagation of electromagnetic waves in the form of additional travel time in signal propagation, this depends on the Total Electron Content (TEC) in the ionosphere and the frequency GPS signal. In positioning high precision with GPS, the effect of the ionosphere must be estimated so that ionospheric correction can be determined to eliminate the influence of the ionosphere on GPS observation. Determination of ionospheric correction can be done by calculating the TEC value using dual frequency GPS data from the reference station or from the model. In making TEC spatial model used polynomial function for certain hours. The processing result shows that the maximum TEC value occurs at 14.00 WIB for February 13rd 2018 with a value of 35,510 TECU and the minimum TEC value occurs at 05.00 WIB for February 7th, 2018 with a value of 2,138 TECU. TEC spatial model shows the red color in Surabaya and its surrounding area for the highest TEC value during the day ranging from 13.00 WIB to 16.00 WIB.
\end{abstract}

Keywords: lonosphere, TEC, TEC Model 


\section{PENDAHULUAN}

Ionosfer adalah bagian dari lapisan atmosfer yang terletak antara 50 sampai $1000 \mathrm{~km}$ diatas permukaan bumi. Ionosfer mengandung elektron yang dapat mempengaruhi propagasi gelombang elektromagnetik berupa tambahan waktu tempuh dalam penjalaran sinyal, hal ini bergantung pada Total Electron Content (TEC) di ionosfer dan frekuensi sinyal GPS.

Efek ionosfer yang terbesar adalah pada kecepatan sinyal, dimana akan langsung mempengaruhi nilai ukuran jarak dari pengamat ke satelit. lonosfer akan memperlambat pseudorange (ukuran jarak menjadi lebih panjang) dan mempercepat fase (ukuran jarak menjadi lebih pendek), dengan bias jarak (dalam unit panjang) yang sama besarnya. Besarnya bias jarak karena efek ionosfer akan tergantung pada konsentrasi elektron sepanjang lintasan sinyal serta frekuensi sinyal yang bersangkutan. Sedangkan konsentrasi elektron sendiri akan tergantung pada beberapa faktor, terutama aktivitas matahari dan medan magnetik bumi.

TEC merupakan jumlah elektron dalam kolom vertikal (silinder) berpenampang seluas $1 \mathrm{~m} 2$ sepanjang lintasan sinyal dalam lapisan ionosfer. pengaruh TEC terhadap sinyal adalah sinyal dari satelit GPS yang melalui ionosfer akan mengalami delay time karena dipengaruhi oleh elektron bebas di ionosfer.

Ionosfer merupakan sumber penting dari jarak dan nilai kesalahan rentang untuk pengguna Global Positioning System (GPS) yang membutuhkan pengukuran akurasi tinggi. Penentuan koreksi ionosfer maka dapat dilakukan dengan perhitungan nilai TEC menggunakan data GPS dual frekuensi dari stasiun referensi atau model.

Dalam penelitian yang akan dilakukan ini adalah analisis nilai TEC ionosfer di Surabaya secara near real time dengan metode komputasi TEC harian dari data GPS dua frekuensi dan dilakukan penggambaran TEC secara spasial pada wilayah Surabaya dan sekitarnya. Hal ini dilakukan untuk memberi informasi karakteristik TEC di Surabaya secara near real time.

\section{METODOLOGI PENELITIAN}

\section{Lokasi Penelitian}

Lokasi penelitian yang dilakukan berada pada lokasi wilayah Surabaya pada koordinat 070 09' - 070 21' LS dan 112 $36^{\prime}$ - 112은 $54^{\prime}$ BT.

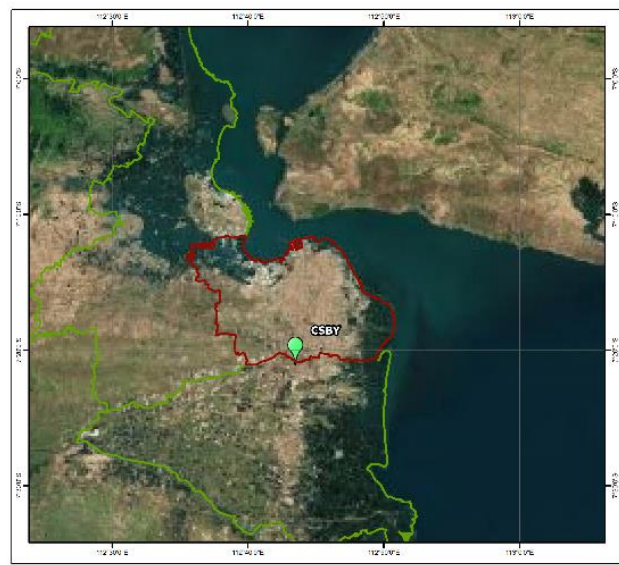

Gambar 1. Lokasi Penelitian (BIG, 2017)

\section{Data dan Peralatan}

- Data

Data yang digunakan dalam penelitian ini meliputi :

1. Data Observasi Rinex (pada tanggal 7 Februari 2018 sampai 9 Februrari 2018 atau Days of Year 38 hingga Days of Year 44) dari stasiun CORS-GPS CSBY.

2. Data Navigasi Satelit (pada tanggal 7 Februari 2018 sampai 13 Februrari 2018 atau Days of Year 38 hingga Days of Year 44).

3. Data bias satelit.

4. Data bias receiver.

5. Data program rdrnx.f dan rdeph.

- Peralatan

Peralatan yang digunakan dalam penelitian ini adalah:

1. Sistem Operasi Windows 10 dan Linux Ubuntu.

2. Bahasa Pemrograman Gfortran.

3. Matlab versi R2013A.

\section{Pengolahan Data}

1. Perhitungan TEC

Melakukan pengolahan data Observasi format RINEX menggunakan program rdrnx.f untuk mendapatkan waktu dan besar nilai STEC dari stasiun pengamatan. Penentuan nilai STEC sesuai dengan satelit yang memiliki orbit dalam wilayah Indonesia dimana hasil tersebut 
disesuaikan dengan data IPP yang telah ditentukan. Dalam perhitungan STEC dilakukan pula koreksi terhadap bias satelit, bias receiver. Dalam penentuan nilai STEC didapatkan dengan rumus :

STEC $=$ TEC $_{\text {observasi }}-$ bias $_{\text {satelit }}-$ biaS receiver $_{\text {. }}$

2. Penentuan IPP

Posisi orbit satelit yang telah didapatkan dari pengolahan menggunakan program rdeph.f pada aplikasi Gfortran kemudian dilanjutkan pengolahan menentukan posisi lonospheric Pierce Point (IPP) menggunakan aplikasi Matlab. Dari posisi lonospheric Pierce Point (IPP) yang telah didapatkan maka lokasi pada titik ionosfer dapat diketahui.

3. Perhitungan VTEC

Perhitungan VTEC terhadap fungsi pemetaan untuk mendapatkan nilai VTEC pada wilayah Surabaya, dengan rumus:

$$
\begin{aligned}
{\left[\begin{array}{c}
\operatorname{STEC}^{1} \\
\operatorname{STEC}^{2} \\
\cdots \\
\operatorname{STEC}^{n}
\end{array}\right]^{T} } & =\left[a_{0}+a_{1}+a_{3}+b_{1}+b_{2}\right] \\
& {\left[\begin{array}{cccc}
m^{1} & m^{2} & m^{n} \\
m^{1} \theta^{1} & m^{1} \theta^{1} & m^{n} \theta^{1} \\
m^{1} \theta^{1^{2}} & m^{1} \theta^{1^{2}} & m^{n} \theta^{2} \\
m^{1} \theta^{1^{3}} & m^{1} \theta^{1^{3}} & \cdots & m^{n} \theta^{3} \\
m^{1} \lambda^{1} & m^{1} \lambda^{1} & m^{n} \lambda^{1} \\
m^{1} \lambda^{1^{2}} & m^{1} \lambda^{1^{2}} & m^{n} \lambda^{2}
\end{array}\right] \text { (2) } }
\end{aligned}
$$

$$
\begin{gathered}
V T E C=a_{0}+a_{1} \theta^{1}+a_{2} \theta^{2}+a_{3} \theta^{3}+ \\
b_{1} \lambda^{1}+b_{2} \lambda^{2}
\end{gathered}
$$

4. Penggambaran Model VTEC

Penggambaran model VTEC dilakukan dengan membatasi pada wilayah Surabaya dan sekitarnya dengan menyajikan tabel nilai VTEC berwarna sesuai dari nilai VTEC yang telah didapat.

5. Tahap Analisa

Analisis dilakukan terhadap grafik dari perubahan nilai TEC dan karakteristik dari nilai TEC dalam harian. Serta analisis terhadap model dari nilai VTEC terhadap wilayah Surabaya dan sekitarnya

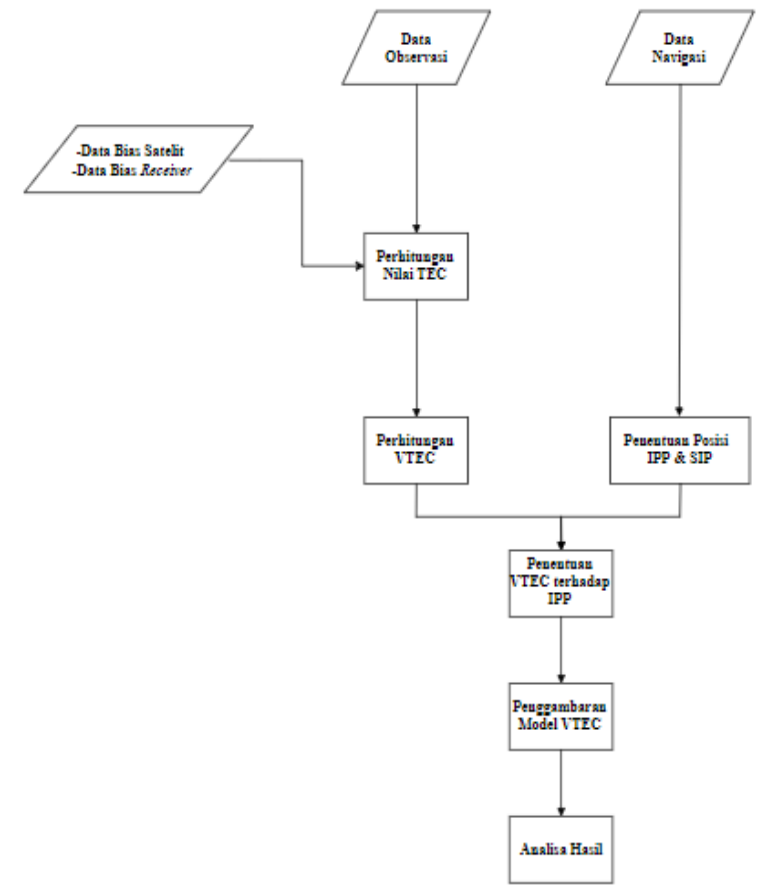

Gambar 2. Diagram Alir Tahapan Pelaksanaan

\section{HASIL DAN PEMBAHASAN}

\section{Analisa Nilai Total Electront Content (TEC) terhadap Waktu}

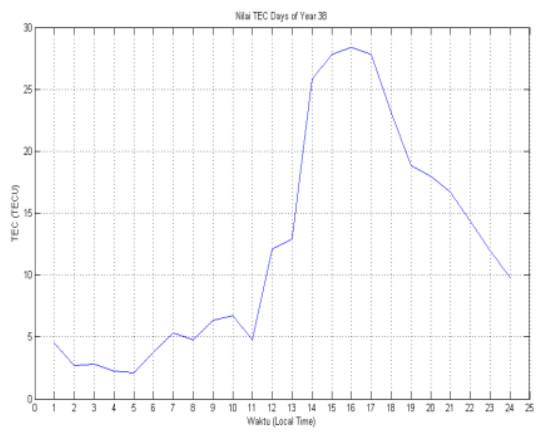

Gambar 3. Grafik Nilai TEC untuk Hari Pertama

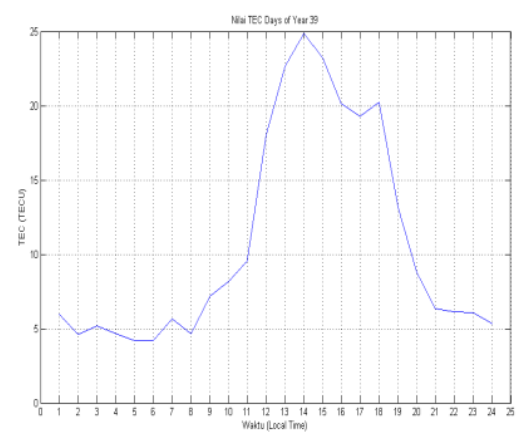

Gambar 4. Grafik Nilai TEC untuk Hari Kedua 


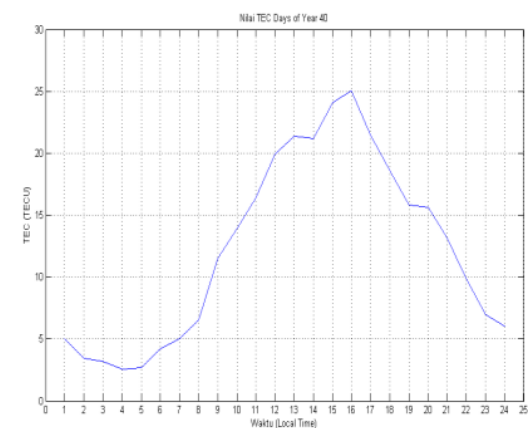

Gambar 5. Grafik Nilai TEC untuk Hari Ketiga

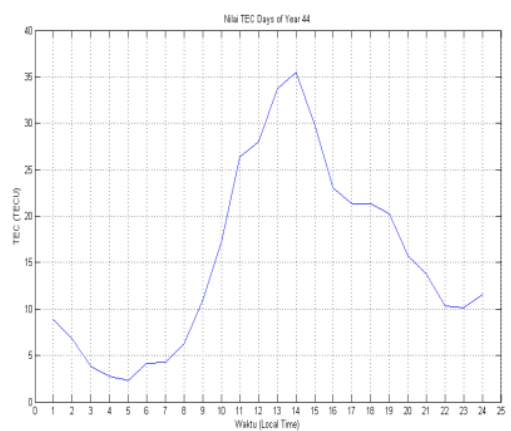

Gambar 6. Grafik Nilai TEC untuk Hari Keempat

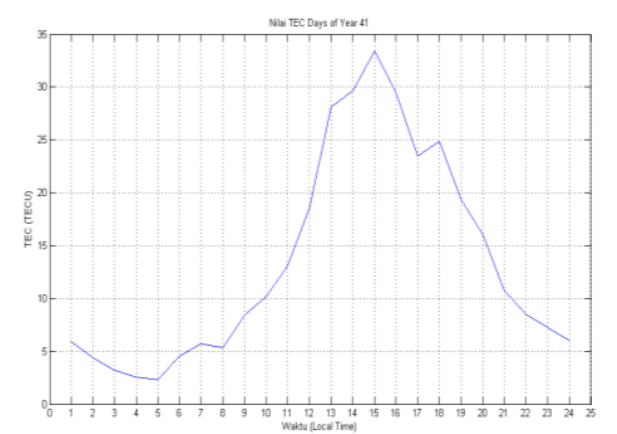

Gambar 7. Grafik Nilai TEC untuk Hari Kelima

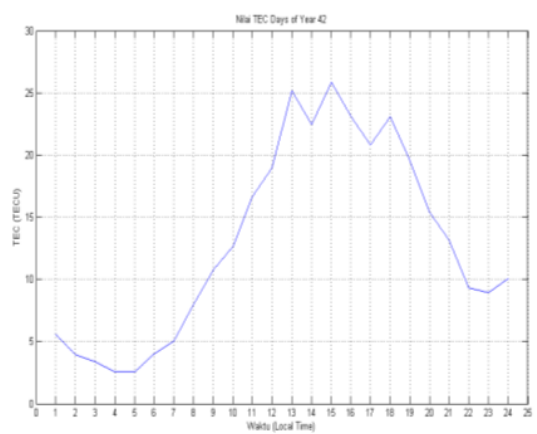

Gambar 8. Grafik Nilai TEC untuk Hari Keenam

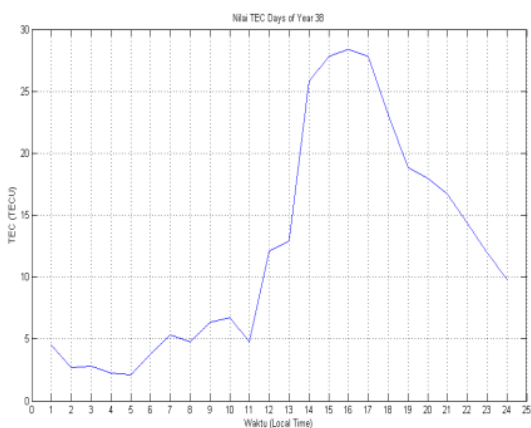

Gambar 9. Grafik Nilai TEC untuk Hari Ketujuh

Berdasarkan gambar 3 hingga gambar 9 maka didapat nilai TEC untuk nilai maksimum dan minimum pada tanggal 7 Februari 2018 hingga 13 Februari 2018 dengan rincian pada tabel dibawah.

Tabel 1. Nilai TEC Maksimum dan Minimum pada Tanggal 7 Februari 2018 hingga 13 Februari 2018

\begin{tabular}{ccc}
\hline Tanggal & Jam & Nilai TEC (TECU) \\
\hline \multirow{2}{*}{ 7 Februari 2018 } & $16.00 \mathrm{WIB}$ & 28,394 \\
& $05.00 \mathrm{WIB}$ & 2,138 \\
\multirow{2}{*}{ 8 Februari 2018 } & $14.00 \mathrm{WIB}$ & 24,889 \\
& $05.00 \mathrm{WIB}$ & 4,166 \\
\multirow{2}{*}{ 9 Februari 2018 } & $16.00 \mathrm{WIB}$ & 25,031 \\
& $04.00 \mathrm{WIB}$ & 2,552 \\
\multirow{2}{*}{ 10 Februari 2018 } & $13.00 \mathrm{WIB}$ & 33,395 \\
& $05.00 \mathrm{WIB}$ & 2,337 \\
11 Februari 2018 & $15.00 \mathrm{WIB}$ & 25,880 \\
& $04.00 \mathrm{WIB}$ & 2,529 \\
12 Februari 2018 & $15.00 \mathrm{WIB}$ & 33,636 \\
& $05.00 \mathrm{WIB}$ & 2,400 \\
13 Februari 2018 & $14.00 \mathrm{WIB}$ & 35,510 \\
& $05.00 \mathrm{WIB}$ & 2,319 \\
\hline
\end{tabular}

Berdasarkan nilai TEC yang didapat, menunjukkan bahwa nilai TEC mengalami kenaikan pada siang hari dimana hal ini disebabkan oleh adanya pengaruh matahari yang menyebabkan jumlah elektron meningkat. Sedangkan nilai TEC minimum terjadi pada malam hari yang disebabkan karena lemahnya aktifitas matahari sehingga jumlah elektron melemah.

\section{Analisa Model Nilai Total Electron Content (TEC)}

Pada gambar 10 merupakan model TEC untuk jam 14.00 WIB dari tanggal 7 Februari 2018 hingga 13 Februari 2018. Dapat diketahui untuk nilai TEC terbesar terjadi pada tanggal 13 Februari 2018 sehingga gambar $10 \mathrm{~g}$ area Surabaya dan sekitarnya berwarna merah. Untuk gambar 10a hingga $10 f$ mengalami keadaan peningkatan nilai TEC 
sehingga area Surabaya dan sekitarnya mengalami perubahan ke warna merah.

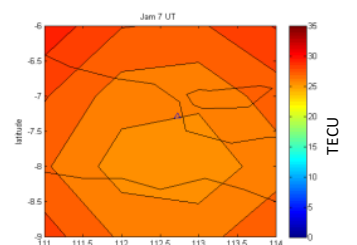

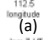

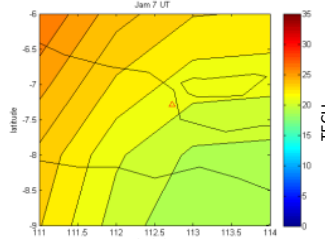

inter
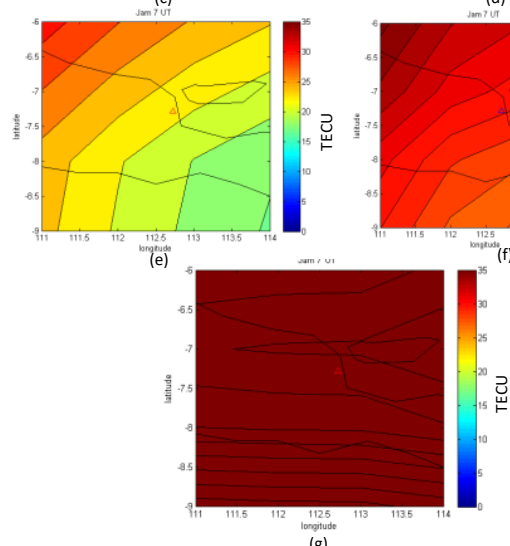

Gambar 10. Model Nilai TEC jam 14.00 WIB

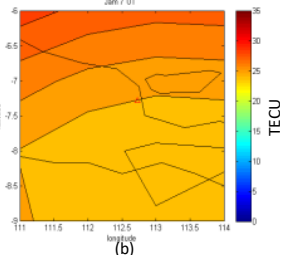

$(b)$

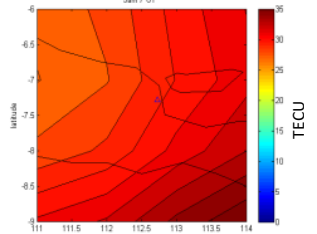

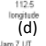
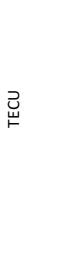

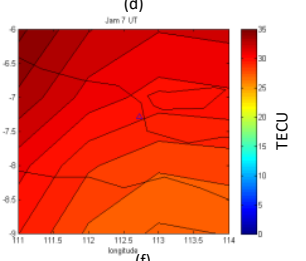

\section{KESIMPULAN}

Berdasarkan pengolahan dan analisis data yang dilakukan, penulis dapat mengambil kesimpulan dalam penelitian ini sebagai berikut:

1. Nilai TEC maksimum terjadi pada tanggal 13 Februari 2018 dengan nilai 35,510 TECU pada jam 14.00 WIB. Sedangkan nilai TEC minimum terjadi pada tanggal 7 Februari 2018 dengan nilai 2,138 TECU pada jam 5.00 WIB.

2. Pergerakan Model TEC untuk jam 14.00 WIB menunjukkan keadaan nilai TEC yang tinggi, hal ini dapat terlihat warna merah yang berada pada area Surabaya dan sekitarnya.

\section{UCAPAN TERIMA KASIH}

Penulis A.N.R mengucapkan terima kasih dosen pembimbing Mokhamad Nur Cahyadi ST, M.Sc, PhD dan Dr. Buldan Muslim, M.Si . dengan dedikasinya telah membimbing dalam berjalannya penelitian ini dan juga kepada instansi Badan
Informasi Geospasial (BIG) karena telah memberikan dukungannya dalam bentuk data sehingga menjadikan penelitian ini selesai sampai akhir. Dengan bantuan yang telah diberikan hingga menjadikan penelitian ini.

\section{DAFTAR PUSTAKA}

Muslim, B. 2009. "Pemodelan TEC Ionosfer Di Atas Sumatra Dan Sekitarnya Mendekati Real Time Dari Data GPS NTUS". Bandung: Pusat Pemanfaatan Sains Antariksa, LAPAN.

Rizal, Mochammad. 2009. "Analisa Nilai TEC (Total Electron Content) pada Lapisan Ionosfer Dengan Menggunakan Data Pengamatan Gps Dua Frekuensi". Surabaya: Jurusan Teknik Geomatika Institut Teknologi Sepuluh Nopember. 